\title{
Speech Genres, of Mikhail Bakhtin ${ }^{1}$
}

The recent Paulo Bezerra's translation of Bakhtin's essay Speech genres (1952-1953) has shed new light on Bakhtin's dialogic theory. Although the translator has already translated this essay that integrates collection Aesthetics of verbal creation (2003), to pull it apart from the collection to relaunch it along with The text in linguistics, in philology and other human sciences (1959-1961), he seeks to illuminate some aspects little emphasized in the old translation.

Bakhtin's theory, due to its gestation process and the difficult access to several of his texts that gradually have been translated in the West, specifically in Portuguese, provides a new theoretical view to each translation. Paulo Bezerra has been one of these translators, with mastery of the Russian language. He seeks to spread Bakhtin's theory elucidating aspects little explicit and which give rise to misinterpretations. Expert of Russian language and literature, he specialized in literary and technical-scientific translation, which offered him more intimate with the Bakhtin's thought, because he also dedicated himself to literary criticism, as proves his academic background. Graduated in Language Arts in Rio de Janeiro, from Gama Filho University, he continued his education by completing master's and doctorate at PUC-RJ, developing themes related to literature. In addition, he defended Habilitation thesis at FFLCH of University of São Paulo and served as a Literature theory professor at the State University of Rio de Janeiro. His researches have always been related to themes discussed by Bakhtin, such as the genesis of the novel, carnivalization, dialogism, Dostoevsky's novels. As a result, he is an eminent researcher with the Russian language in which Bakhtin expressed himself concerning dostoievskiana's works focusing the development of his dialogical theory. Thus, Bezerra is characterized as a privileged interpreter of Bakhtin's thought, which is revealed in his magnificent translation jobs. The fact of translating and retranslating, reevaluating his translations due to a new context of both research and researchers marks his immersion in Bakhtin's theory, for which the utterance, although concluded in its final point, is always opened to possible interpretations, concluding in every moment of his reading. In order to translate, Bezerra closely approaches the author and his language and as new Bakhtin's texts appear, consequently, new forms of assimilation of his theory emerges as well.

As the theoretical exposure from this language philosopher does not objective to make easier his concepts about language, it is necessary that the interpreter immerses in his universe to properly understand its concepts and its implications. This is the task which Bezerra proposes himself whenever translating and retranslating the same texts. This project had already been announced with the publishing of Novel Theory I: The stylistic (2015), published by Editora 34, one of the essays that integrates Literature issues and aesthetics: a novel theory (1975), a collection of written texts at different times. Thus, this publication of Speech genres follows Bezerra's proposal to present new translations due to the publication of Collected works (1997) by Bakhtin, which was organized in Russia by Sergei Botcharov. The translation of Speech genres is part of the dismemberment project Aesthetics of verbal creation, collection of essays prepared at different moments, in four books, as Bezerra explained: "Actually, Aesthetics of verbal creation is not a thematically uniform book; there are three books in one, all different from each other by the objects

1 Miriam Puzzo. Professor at undergraduate and Post-Graduate studies in UNITAU. 
of analysis and reflection, as well as two texts about Dostoevsky and four others about different topics of human sciences. By my suggestion and acceptance of Bakhtin's heirs, Editora 34, official rights holder of Bakhtin's work in Brazil, decided to dismember Aesthetics of verbal creation in four books and publish them separately, starting by Speech genres. "

In addition to this essay, dating from 1952-1953, that is the title of this edition, Bezerra adds the essay The text in linguistics, philology and other human sciences (19591961), translated by Bezerra himself in Aesthetics of verbal creation (2003), which takes as its title The problem of text in linguistics, philology and other human sciences. The reason for the new version of the title is thus justified by the translator: "In my old translation of Aesthetics of verbal creation, the title of this heading was 'The problem of text in linguistics, philology and other humanities ...'. For this new edition I decided to abolish 'the problem' because they consider it a Russian bad habit style, whose suppression has no interference in reflection of Bakhtin "(p. 71).

Besides these two essays, there is the addition of two new texts, "Dialogue I" (1950) and "Dialogue II" (1952), published in Russia, in volume 5 of Bakhtin's work, by Russkie Slovari publisher in 1997. These are part of Bakhtin notes that can be found in his collection. In these notes, the Russian philosopher exposes his reflections on language and language as a constitutive gestation part of Speech Genres essay. They also present reflections as part of projects that did not come to fruition. As the translator explains: "At first glance they are drafts of what would be the final text 'Speech genres', but in a careful reading, it is realized that Bakhtin goes beyond the designed book. Several themes presented there, integrate 'Speech genres' ", others are ideas that Bakhtin intended to develop, deepening his vast theory of genres and expanding it to the specifically literary genres and even other writing genres." (P. 111). By these fragments, with revealing ideas in gestation, it is possible to relate concepts that sometimes are not clear or are not made explicit in the theoretical exposure of the completed essays. As Bezerra evidences: "The themes that are outlined or developed there, will really help the Brazilian reader to understand the complex intricacies of 'Speech genres', besides inserting them in the laboratory of Bakhtin's ideas." (P.111).

In the general organization of this publication, the summary revealed by the care of the translator, with the sources, notes, explanations of the translation process. It is constituted by: "Notes on the Brazilian edition", "Speech Genres," "The text in linguistics, philology" and the attached "Dialogues I" and "II Dialogues" that are preceded by translator's note about these texts and, finally, the "Postscript" by Paulo Bezerra. This edition also features short texts "About the Author" and "About the translator."

Compounding the flaps of the Beth Brait book, being a researcher on Bakhtin theory, she makes her comments regarding this new translation, justifying it. Brait manifested herself in this way: "Translation is an established unique relationship between a source text and a context of arrival, implying ways of reading and rereading a work and its author." And this is one of the merits of this translation.

In the notes there is a description of the selection of the essays, after; there are two essays that present some innovations in writing. As it is possible to observe, the translator seeks to update his translation according to the Brazilian reader, reviewing some aspects from the previous translation.

One of the differences is regarding the footnotes that replace the end of the book in Aesthetics of verbal creation (2003). This change immediately gives the reader an important piece of information, making it easier to read. 
It also seeks better ways, for example, of replacing the term "ideology" in the old version by "world view" in the current translation. Such substitution avoids connotations or a different bias from the one proposed in the original. Moreover, as the translator himself explains, it replaces "enunciação" by "enunciado" to avoid certain theoretical misunderstanding, given that in the original text, Bakhtin uses the two terms interchangeably to refer to the same communicative process. In the words of the translator: "In previous translations, perhaps influenced by other language currents, I had translated the term viskázivanie by 'utterance' when it meant the act or immediate production of speaking or speech. The careful and analytical rereading I made from the texts for this edition, made me realize that I had indeed committed a serious impropriety. For Bakhtin, viskázivanie or utterance is not to mere act of producing speaking or speech; it is much more than that. Utterance is the link (NB: the link and not a link) key to the communication chain, and is endowed with a historical and cultural communicative three-dimensionality that brings together past (the antecedent, history), present (the continuum) and the future (the consequent) from the communication process as a phenomenon of the perennial culture in its substantiality and open as a form of existence and communication among people in the historical development and open unity of culture and history"(p.153). This is a crucial aspect to establish the difference of this concept in relation to other theoretical points, occurring frequently conceptual misunderstanding between beginners and even among researchers that focus on the study of speech genres. The comment of the translator is essential and enlightening, showing a mastery way of reading the theory.

It also innovates in adapting terms that do not have correspondents in Portuguese, creating neologisms. This is the case, for example, the term "compreendedor" " used in the page of the section 113, the Dialogue I: "Understanding does not repeat or dub the speaker, it creates its own conception, its own content; each speaker and each "compreendedor" remains in his own world; the word only provides the direction, the cone apex. "To justify this neologism, thus manifests the translator: "Although the term 'compreendedor' is not in dictionaries, there is no other term in Portuguese able to accurately convey the meaning of the speaker dyad -compreendedor [...] basis of Bakhtin's conception of dialogue. With the insertion of 'compreendedor' as required pair of speaker-listener relationship, Bakhtin appoints its difference in the face of traditional linguistics, in which the listener was limited to hearing and was never considered a speaker. "

Similar feature occurs with the term "princípio"4 that Bezerra employs for closer translation of the original Russian, although this term creates a neologism in Portuguese. In justification for this use, the translator explains: "In order to give more lightness to the language of the texts, I had to appeal to 'a daring action'. In Portuguese there is no adjective for the word 'princípio' as a fundamental logical proposition on which is based the thought (Houaiss). The Russian uses, sometimes as a bad habit, the Latin word principio in short word of printsipialno that can have adverb value (principalmente) $)^{5}$ and can be an adjectival phrase 'de princípio'. As Bakhtin uses it in the sense of logical proposition, I decided to translate printsipialno by "principal", instead of using the adjectival phrase 'de princípio' that in a formed sequence with other adjectives, often breaks the flow of speech, making it heavy"(p.152).

2 English equivalent - "utterance"

3 English equivalent - "a person who understands"

4 English equivalent - "principle"

5 English equivalent - "mainly" 
There are other substitutions described by the translator that respond in a way to the reader, making it easier to read. Among the vocabulary adaptations it is possible to find the replacing of the Latin phrase "mutatis mutandis", which is on page 272 of the Aesthetics of verbal creation, for " change and addenda" on page 25 of this issue. This choice is due to the translator's dialogue with the reading public, made not only by researchers, but also by students little accustomed to Latin expressions, given that Latin is no longer a compulsory subject of undergraduate and much less of the courses of primary and secondary education as it was until the seventies of the twentieth century. Therefore, the translator seeks to facilitate the contact of the younger reader with Bakhtin theory, presenting a less formal language without affecting the original. In addition to the appropriateness of vocabulary, Bezerra seeks to be more direct and objective, as he says in the Postscript. A good example is found in this section: "The issue of the clause nature is one of the most complex and difficult in the linguistics", page 276 of the Aesthetics of verbal creation, replaced by the more direct writing "(The nature of the clause is one of the most complex and difficult issues in linguistics ....) “(p. 31).

Some other changes, less meaningful, are described by Bezerra in order to improve the speech in a clearer and more direct way: "all" / "whole" by "totality"; "artistic" by "fictional", "semantic" by "sense"; "Dialogic setting" by "dialogical" - in the latter case "to keep with the utmost originality to Bakhtin's terminology “ (p.152) as the translator justifies. It also replaces "understanding" by "interpretation" when this term refers to literary work.

There are several factors that make this translation meaningful for researchers and readers interested in the theory of speech genres or dialogic as a theoretical principle. Although the original texts are the same, this new translation offers a differentiated approach. Firstly by unlinking Speech genres of the collection of essays about other topics, more targeted to literature and developed at different moments. Secondly, it highlights the concepts and theoretical categories related to genres, emphasizing other concepts developed in other essays. So despite being the same original text, it is another in function of the new context, a new translation purpose, updated to the contemporary reader. In such case, as a dialogical theory, it demonstrates that the utterance is unrepeatable, even if it is identical, it changes the context, changes the receivers, changes the communicative proposal and it changes the tone (p.48-49). It is Bakhtin's translator that Bezerra represents at the moment he re-evaluates and updates his translation from thirteen years ago.

Thus, this new edition of Speech genres is important for researchers and scholars of Bakhtin's theory, because, in addition to the translation adjustments, it counts on the explanatory translator Postscript and two unpublished texts that support the understanding of theory and ideas that sustain it, especially with regard to the concept of living language and metalanguage.

\section{Bibliography}

Bakhtin, M. M. Speech Genres. (Organization, translation, postscript and Paulo Bezerra's notes, Russian edition notes Serguei Botcharov), 1st edition, São Paulo: Editora 34, 2016, 176p. 